\title{
A Histologic Assessment of the Influence of Low-Intensity Laser Therapy on Wound Healing in Steroid-Treated Animals
}

\author{
EUDORO S. PESSOA, D.D.S., M.S., ${ }^{1}$ RONALDO M. MELHADO, D.D.S., Ph.D., ${ }^{1}$ \\ LETÍCIA H. THEODORO, D.D.S., Ph.D., ${ }^{2}$ and VALDIR G. GARCIA, D.D.S., Ph.D. ${ }^{1,2}$
}

\begin{abstract}
Objective: The aim of the present study was to evaluate the effect of low-intensity laser therapy on the wound healing process treated with steroid. Background Data: Various biological effects have been associated with low-level laser therapy (LLLT). Materials and Methods: Forty-eight rats were used, and after execution of a wound on the dorsal region of each animal, they were divided into 4 groups $(n=12)$, receiving the following treatments: G1 (control), wounds and animals received no treatment; G2, wounds were treated with LLLT; G3, animals received an intraperitoneal injection of steroid dosage ( $2 \mathrm{mg} / \mathrm{kg}$ of body weight); G4, animals received steroid and wounds were treated with LLLT. The laser emission device used was a GaAIAs (904 $\mathbf{n m )}$, in a contact mode, with $2.75 \mathrm{~mW}$ gated with $2.900 \mathrm{~Hz}$ during $120 \mathrm{sec}\left(33 \mathrm{~J} / \mathrm{cm}^{2}\right)$. After the period of 3, 7, and 14 days, the animals were sacrificed and the parts sent to histological processing and dyed using hematoxylin and eosin (HE) and Masson trichromium (MT) techniques. Results: The results have shown that the wounds treated with steroid had a delay in healing, while LLLT accelerated the wound healing process. Also, wounds treated with laser in the animals treated with steroid presented a differentiated healing process with a larger collagen deposition and also a decrease in both the inflamatory infiltrated and the delay on the wound healing process. Conclusion: LLLT accelerated healing, caused by the steroid, acting as a biostimulative coadjutant agent, balancing the undesirable effects of cortisone on the tissue healing process.
\end{abstract}

\section{INTRODUCTION}

W ITH THE ADVENT OF THE FIRST laser emission device created by Theodore Maiman ${ }^{1}$ around 1960, a new era arose in the prevention area, therapeutic and surgical, not only for Medicine but also for Dentistry. Low-level laser therapy (LLLT) in the last years has been the study aim of many researchers around the world. ${ }^{2-10}$ Previous studies have evaluated the LLLT effectiveness in a variety of experimental models, both in animals and humans or in different pathological conditions. Other studies, however, emphasize that depending on the applied dose, wavelength, irradiation time and also the conditions of the treated tissue, different biological answers can be achieved, ${ }^{11}$ causing an increase in cellular metabolism, enhancing the regenerative potential besides promoting an anti-inflammatory effect with analgesia and vasodilatation. ${ }^{11-13}$ On the other hand, the wound tissue healing process may be slowed under various conditions, including tobacco, diabetes, bad nutrition, as well as the daily use of cortisone such as dexametasone, a steroids antiinflammatory which inhibits the wound tissue healing process on the condroitinsulfate synthesis or directly inhibiting the collagen formation. ${ }^{14-16}$

So the purpose of this study is to evaluate from the histological point of view, the wound healing process in open wounds provoked on the back of rats, submitted to the cortisone treatment (sodium phosphate of dexametasone) associated or not with LLLT. 


\section{MATERIALS AND METHODS}

The present study was approved by the Ethics Committee of the School of Dentistry in Araçatuba, UNESP. Forty-eight sound rats (Rattus norvegicus, albinus, Wistar) weighing approximately $220 \mathrm{~g}$, were submitted to the operative procedures in this study.

After anesthesia with chloral hydrate (400 mg/kg-ip), via peritonea, the dorsal region of all the animals were trichotomyzed following disinfection with alcohol at $70 \%$. On the medial dorsal portion a circular area of skin (approximately $8 \mathrm{~mm}$ of diameter) was removed with a punch and placed on the medial portion of the median sagital plane. The animals were divided into four groups with 12 animals in each and received the following treatments: Group 1 (G1), the animals had no local nor systemic treatment and were considered as control wounds; Group 2 (G2), the wounds were treated immediately after they were made with a low intensity laser ( $\mathrm{GaAlAs}$ ); Group 3 (G3), the animals were treated with a daily sodium phosphate of dexametasone intraperitoneal injection $(2 \mathrm{mg} / \mathrm{kg}$ of body weight) during all the experimental period and; Group 4 (G4), the animals received the same treatment as in G3, but the tissue wounds were treated with the GaAlAs laser at the same conditions as in $\mathrm{G} 2$.

The low-intensity laser used in this study was a galliumaluminium-arsenium (GaAlAs; cavity D1; Space Laser Ibérica) with a wavelength of $904 \mathrm{~nm}$, in a contact mode, with power of $2.75 \mathrm{~mW}$, gated with $2900 \mathrm{~Hz}$ during $120 \mathrm{sec}$ per point, totaling $0.33 \mathrm{~mJ}$ per point with a spot size of approximately $0.007 \mathrm{~cm}^{2}$, fluency of $47.14 \mathrm{~J} / \mathrm{cm}^{2}$, and $2.97 \mathrm{~J}$ of total energy.

The laser irradiation was performed in eight distinct regions around all the wound margin and in a central point scanning all over the wound (Fig. 1).

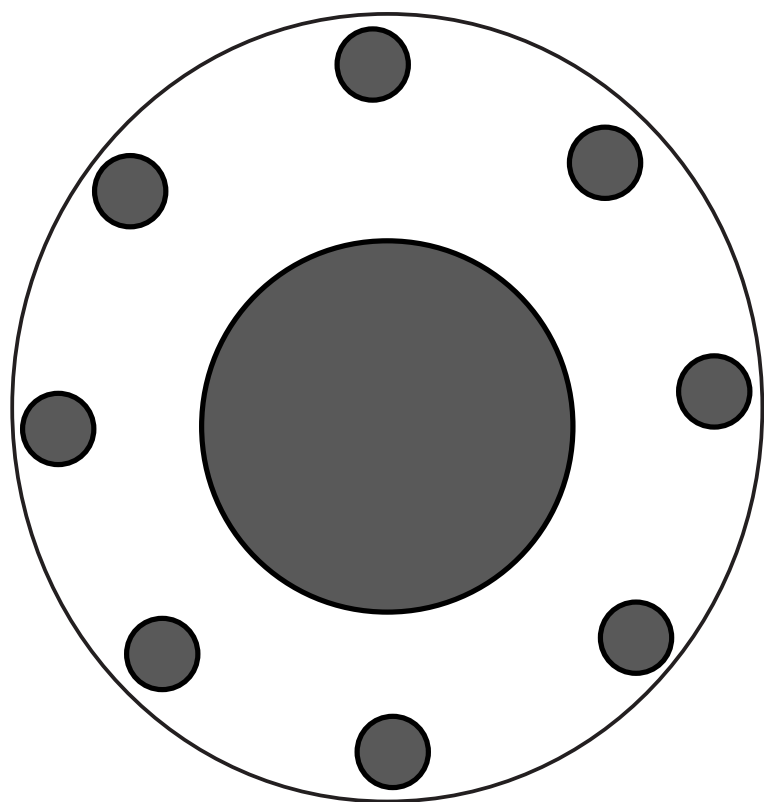

FIG. 1. Schematic drawing representing the wound laser irradiation. The irradiation was made in eight sites at the wound margins and using a scanning method on the central area (0.33 mJ per site).
After 3, 7, and 14 days of the surgery act and treatment, four animals in each group were sacrificed using an overdose of anesthetic solution.

The obtained pieces were fixated in a $10 \%$ formaldehyde solution for a period of $24 \mathrm{~h}$ at a minimum. After this they went through routine lab procedures until being set in paraffin, oriented in a way to allow transversal sections, semi-serial, of $6 \mu \mathrm{m}$ thick, and were dyed with hematoxylin and eosin (HE) and Masson trichromium (MT) for histological analysis.

\section{RESULTS}

Qualitative and quantitative conditions of the wound healing process for the histological description results were considered both for the superficial and deeper areas of the surgical wound.

\section{3-day follow-up}

The results obtained in this present study indicated that the wounds from the control group (G1) had a crust and an intense lymphocyte inflammatory infiltrate (Fig. 2). The wounds of the rats treated with the cortisone $(\mathrm{G} 3)$ presented a delay in the healing process characterized by a discrete vasodilatation and lymphocyte inflammatory infiltrate (Fig. 3). The opposite happened to the group treated only with laser (G2), where the healing was more distinguished with less vasodilatation and a discrete mononuclear inflammatory infiltrate more evident on the deeper part of the wound (Fig. 4) showing during this period a resemblance to the ones treated with cortisone and laser (G4) (Fig. 5). During this postoperative period the hue by the Masson trichromium did not reveal the presence of the deposited collagen in any of the specimens.

\section{7-day follow-up}

During this period the wounds from the control group (G1) were almost totally filled by a granulation tissue with moderate lymphocyte inflammatory infiltrate and the epithelial proliferation on the margins of the wound was still discrete. The wounds from group 3 (G3), treated with cortisone, revealed a delay in the healing process with an intense vasodilatation

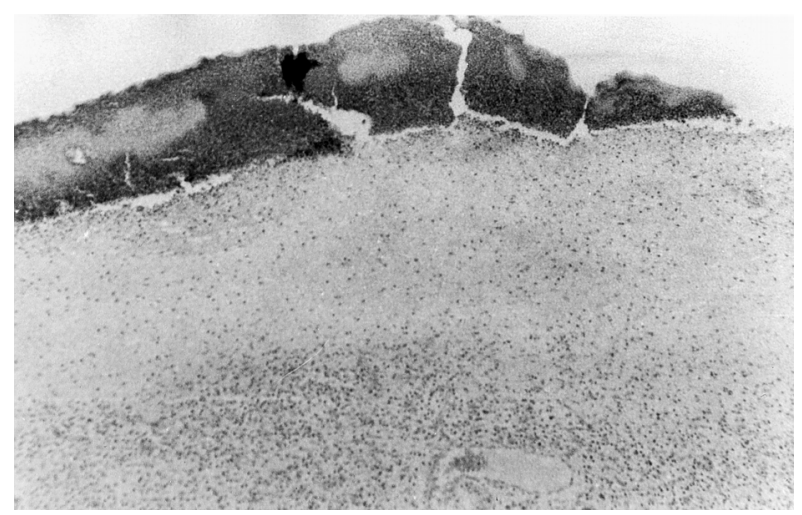

FIG. 2. G1 (control). Presence of a crust covering all the wound and intense lymphocyte inflammatory infiltrate3-day-follow-up (HE; original magnification, $\times 20$ ). 


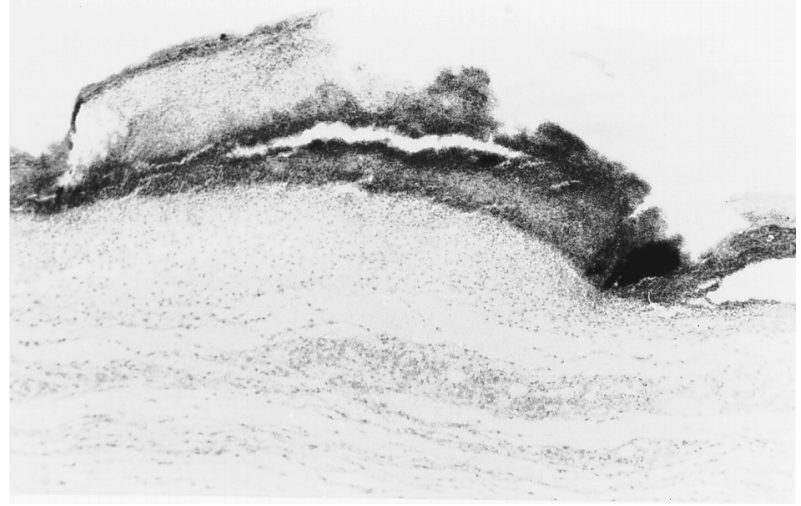

FIG. 3. G3 (cortisone). The wounds presented a delay on the healing process, presence of a crust and blood clot, vasodilatation and discrete lymphocyte inflammatory infiltrate-3-dayfollow-up (HE; original magnification, $\times 20)$.

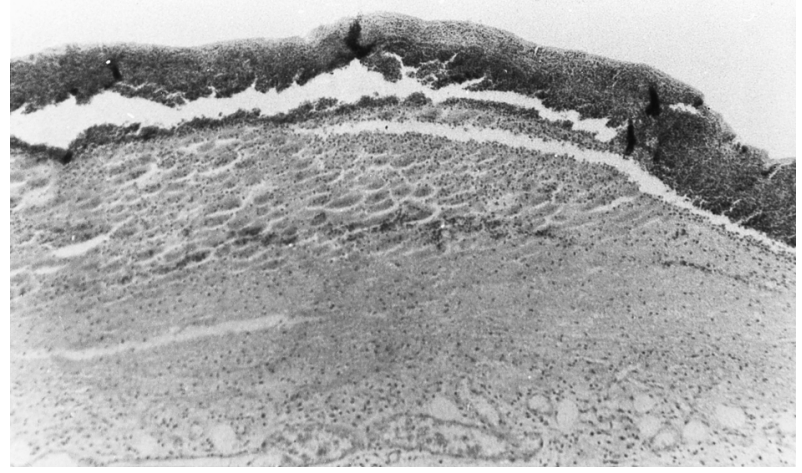

FIG. 4. G2 (laser). Crust presence on the wounds, blood clot, less vasodilatation on the connective tissue and discrete mononuclear inflammatory infiltrate more evident at the deeper portion of the wound-3-day-follow-up (HE; original magnification, $\times 20)$.

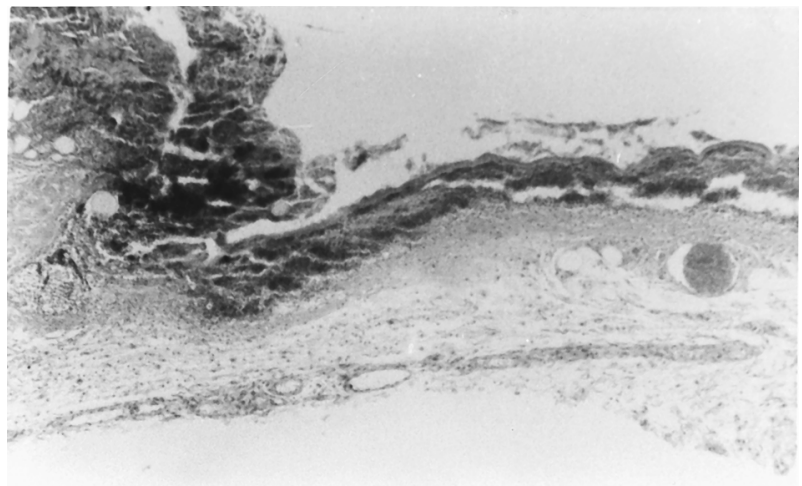

FIG. 5. G4 (cortisone + laser). Presence of crust, blood clot, discrete vasodilatation, and lymphocyte inflammatory infiltrate on the wounds-3-day-follow-up (HE; original magnification, $\times 20)$.

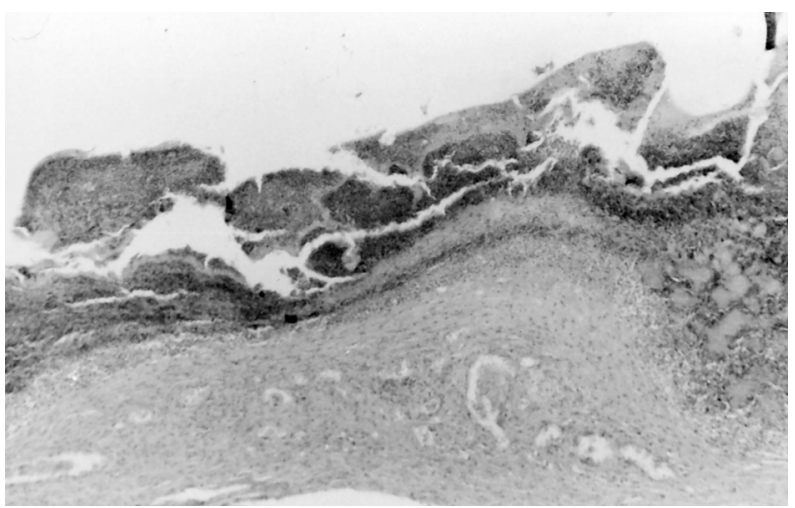

FIG. 6. G3 (cortisone). Presence of crust, blood clot, intense vasodilatation and moderate lymphocyte inflammatory infiltrate on the wounds-7-day-follow-up (HE; original magnification, $\times 20)$.

(Fig. 6), but the ones from the laser group (G2) showed that the healing granulation tissue filled most of the wound extension and it was much more differentiated. The wounds treated with cortisone and laser $(\mathrm{G} 4)$ revealed a discrete amount of inflammatory infiltrate and the granulation tissue was more differentiated (Fig. 7).

\section{4-day follow-up}

During this period the wounds from the control group (G1) presented a granulation tissue filling the wound totally and still presented a discrete inflammatory infiltrate. The epithelium covered all the wound and had a few layers of cells without delineating epithelial projections while the ones from the laser group (G2) showed less amount of blood vessels, a reduction on the inflammatory cells and the epithelium presented with more layers delineating epithelial projections (Fig. 8). But the wounds of the rats treated with cortisone (G3) still presented a delay on the wound tissue healing process chronology by presenting on the healing granulation tissue a great amount of blood vessels and also a moderate inflammatory infiltrate

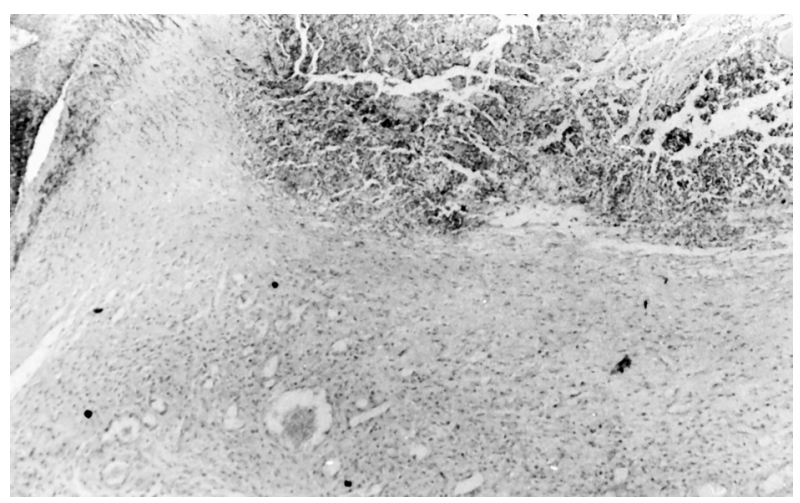

FIG. 7. G4 (cortisone + laser). Evidence of crust presence covering part of the wound, a more differentiated granulation tissue with a discrete amount of inflammatory infiltrate on the wounds-7-day-follow-up (HE; original magnification, $\times 20$ ). 


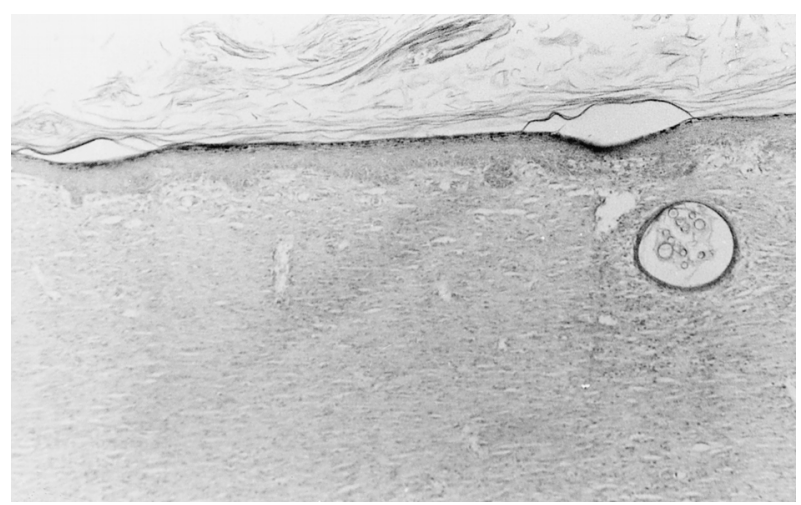

FIG. 8. G2 (laser). Epithelial projections, less vascularization, and reduction of the inflammatory cells number-14-dayfollow-up (HE; original magnification, $\times 20)$.

(Fig. 9). It is important to note that during this period the wounds treated with cortisone and laser (G4) presented a granulation tissue in a differentiated advanced stage and the epithelial tissue had a thick appearance covering the wound extension (Fig. 10).

Through the Masson trichromium hue it is possible to observe that the biggest amount of deposited collagen was evidenced on the wounds treated with laser (G2) (Fig. 11) followed by the ones from the group 4 (treated with cortisone and laser) (Fig. 12). The wounds treated only with cortisone (G3) the collagen deposition was discrete (Fig. 13).

\section{DISCUSSION}

It is possible to verify from the results of the present study that the newly formed granulation tissue on the wounds treated with sodium phosphate of dexametasone, when compared to their correspondent controls, demonstrates a sharp delay on the development being the fibroblastic proliferation practically inhibited during all the analyzed periods, which are in agreement

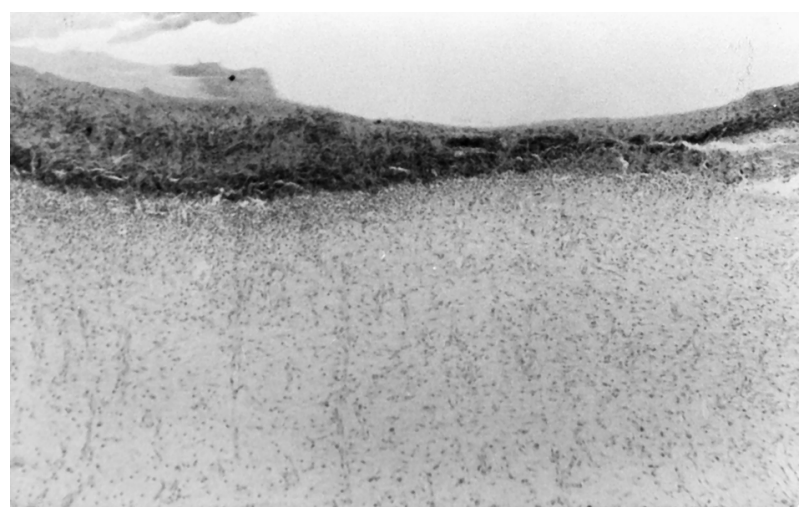

FIG. 9. G3 (cortisone). Presence of crust and blood clot, granulation tissue with great amount of blood vessels, and moderate inflammatory infiltrate-14-day-follow-up (HE; original magnification, $\times 20)$.

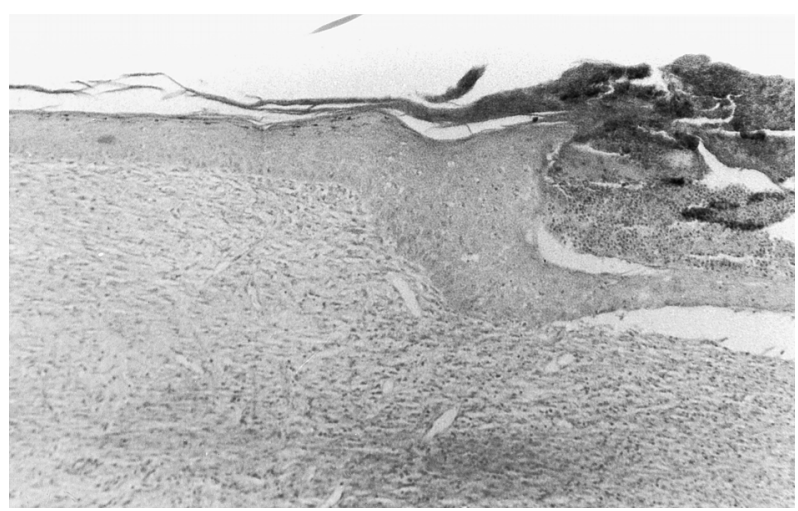

FIG. 10. G4 (cortisone + laser). Wound covered by an epithelial tissue, remaining crust, granulation tissue with moderate amount of blood vessels and discrete lymphocyte inflammatory infiltrate-4-day-follow-up (HE; original magnification, $\times 20$ ).

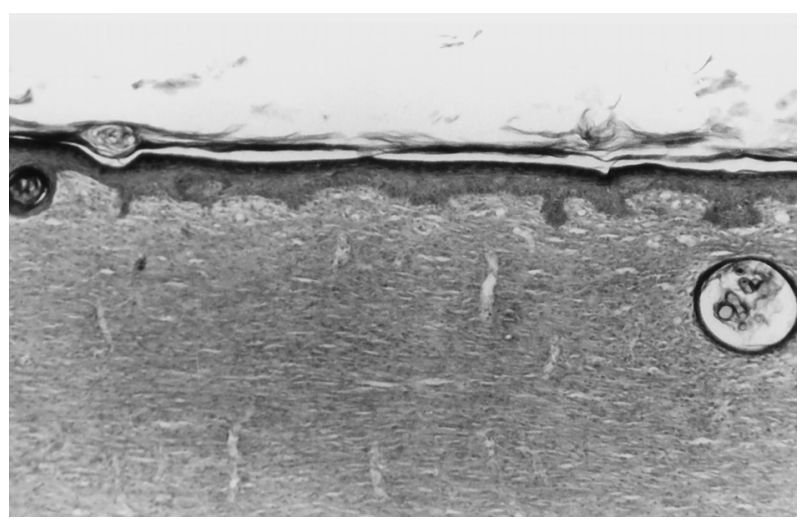

FIG. 11. G2 (laser). Intense collagen deposition on the granulation tissue-14-day-follow-up (TM; original magnification, $\times 20)$.

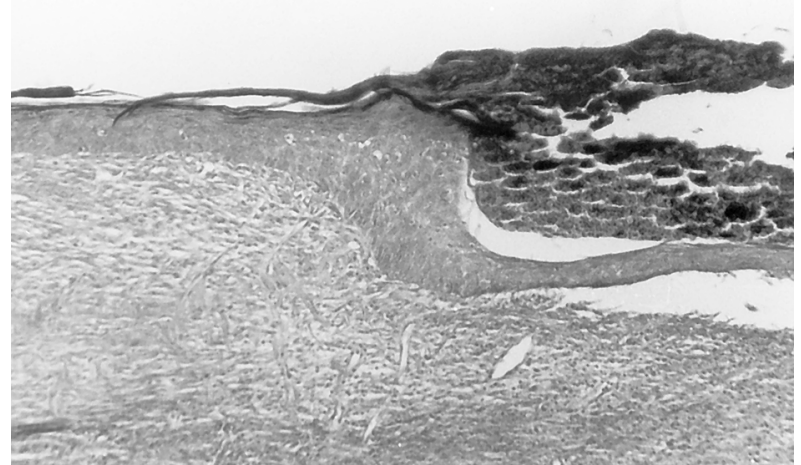

FIG. 12. G4 (cortisone + laser). Moderate collagen deposition on the granulation tissue-14-day-follow-up (HE; original magnification, $\times 20$ ). 


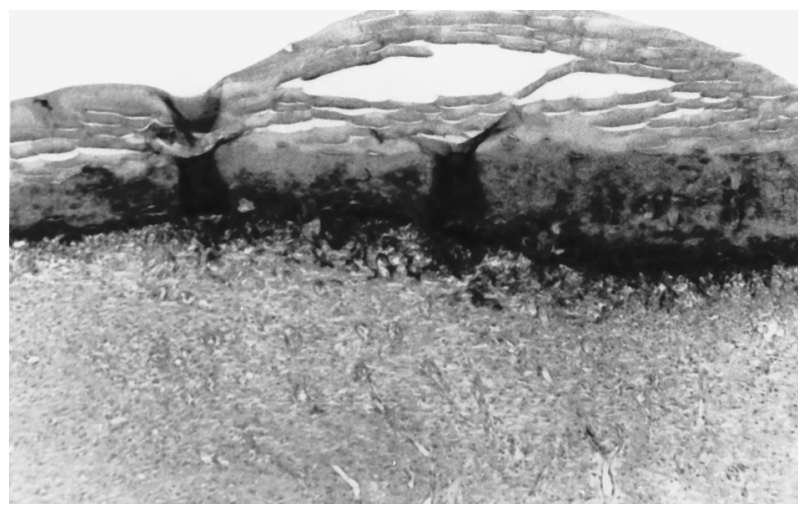

FIG. 13. G3 (cortisone). Discrete collagen deposition on the granulation tissue-14-day-follow-up (TM; original magnification, $\times 20)$.

with other studies. ${ }^{15-17}$ Both the fibroblastic inhibition and the granulation tissue intercellular substance inhibition from the glycocorticoids, although not much known, suggest a relationship with the protein metabolism. ${ }^{17}$ According to Ruch ${ }^{18}$ the dexametasone acts directly on the mesenchyme inhibiting the mitotic activity probably through the partial inhibition of the DNA synthesis. This author still suggests that when the glucose concentration is increased the dexametasone inhibition capacity is quite reduced concluding this way that the glycocorticoids interfere on the carbohydrates metabolism.

The delay on the granulation tissue formation on the animals treated with dexametasone (G3) was evident in our results. It is suggested then that the sodium phosphate of dexametasone acts on the granulation tissue producing a delay on the healing process where the fibrin formation diminishes with the decrease of the granulocytes and macrophages phagocytosis, the blood flow on the tissue is also decreased and as a consequence the granulation tissue formation too. 19 Wali states that all the glycocorticoids inhibit growth, regeneration and healing of the cellular and intercellular components of the dermal connective tissues when they penetrate through the skin and the resultant atrophy is a logical manifestation of the action of these components. 19

It was also evident in this present study that the low intensity laser therapy besides having a biostimulation effect on the open wound healing process without the medicaments effect also showed its potential as a coadjutant agent based on the results found on the wounds of the rats treated with cortisone intraperitonial injection.

Our results agree with several authors who describe the beneficial effects of low intensity laser use on the wound tissue healing process. ${ }^{20-24}$ It is believed that the accelerating wound healing process laser effect is related to the low intensity laser radiation showing the capacity to induce the epithelial cells mitotic activity, ${ }^{25}$ modify the capillary density, ${ }^{26}$ stimulate the local microcirculation ${ }^{27}$ and mainly to increase the collagen synthesis and cell proliferation. ${ }^{28-30}$

Another factor to consider in this study is that the power intensity used was relatively low and it promoted a beneficial effect on the normal tissues with delayed healing. Our results are in agreement with the theories that the LLLT irradiation at cer- tain wavelengths may stimulate cell proliferation, but only at certain combinations of exposure parameters of energy fluency and power density. At higher laser energy doses, decreased proliferation has been reported at high-energy fluencies and irradiance. ${ }^{29-33}$

Loevschall and Arenholt-Bindslev ${ }^{31}$ suggest that near infrared low level laser irradiation of human fibroblast cultures increases cellular proliferation dependent on the radiant exposure time, and the clinical significance of these findings require further elucidation before a rational principle of laser treatment and dosimetry can be established.

Our results demonstrated that the laser promoted a biostimulative effect that surpassed the dexametasone inhibitory effects, although with the methodology used in the present study it is not possible for us to clarify the exact mechanism that the laser compensated this inhibitory effect over the intercellular matrix and also the fibroblastic proliferation.

It is suggested that the laser biostimulative effect with the power intensity used in this study on the wounds with the delayed or normal healing may be associated with the absorption of the 904-nm wavelength used (infrared) by the cytochrome oxidase, ${ }^{34}$ which is suggested to be one of the primary photoreceptors of the respiratory chain ${ }^{31}$ increasing the ATP production, the cellular metabolism and the DNA synthesis generating thus a fibroblastic proliferation increase which is according with the Loevschall and Arenholt-Bindslev findings. ${ }^{30}$

\section{CONCLUSION}

The results allowed us to observe that the skin wounds irradiated with the laser within the present methodology and the irradiation parameters is capable of promoting a decrease on the inflammatory infiltrate; a larger epithelial differentiation on the treated wounds; a more differentiated healing process with more collagen deposition and decrease of the cicatrisation delay produced by the dexametasone. From these facts it is possible to conclude that the low intensity laser can be optimized for the use in wounds in patients who do not use medications as well as it can also be associated with other therapeutic ways, enforcing thus its use indication for patients who may present a delay on the wound tissue healing process as in diabetic patients and mainly the ones who require the use of corticoids routinely.

\section{REFERENCES}

1. Maiman, T.H. (1960). Stimulated optical radiation in ruby. Nature 187, 493-494.

2. Schlager, A., Kronberger, P., Petschke, F., et al. (2000). Lowpower laser light in the healing of burns: a comparison between two different wavelengths $(635 \mathrm{~nm}$ and $690 \mathrm{~nm})$ and a placebo group. Lasers Surg. Med. 27, 39-42.

3. Lilge, L., Tierney, K., and Nussbaum, E. (2000). Low-level laser therapy for wound healing: feasibility of wound dressing transilumination. J. Clin. Laser Med. Surg. 18, 235-240.

4. Maegawa, Y., Itoh, T., Hosokawa, T., et al. (2000). Effects of nearinfrared low-level laser irradiation on microcirculation. Lasers Surg. Med. 27, 427-437. 
5. Dörtbudak, O., Haas, R., and Mailath-Pokorny, G. (2000). Biostimulation of bone marrow cells with a diode soft laser. Clin. Oral Implants Res. 11, 540-545.

6. Smith, R.J., Birndorf, M., Gluck, G., et al. (1992). The effect of low-energy laser on skin-flap survival in the rat and porcine animal models. Plast. Reconstr. Surg. 89, 306-310.

7. Hall, G., Anneroth, G., Schennings, T., et al. (1994). Effect of low level energy laser irradiation on wound healing. An experimental study in rats. Swed. Dent. J. 18, 29-34.

8. Taubé, S., Piironen, J., and Ylipaavalniemi, P. (1990). Heliumneon laser therapy in the prevention of postoperative swelling and pain after wisdom tooth extraction. Proc. Finn. Dent. Soc. 86, 23-27.

9. Carrillo, J.S., Calatayud, J., Manso, F.J., et al. (1990). A randomized double-blind clinical trial on the effectiveness of helium neon laser in the prevention of pain, swelling and trismus after removal of impacted third molars. Int. Dent. J. 40, 31-36.

10. Wong, E., Lee, G., Zuckerman, J., et al. (1995). Sucessfulll management of female office workers with "repetitive stress injury" or "carpal tunnel syndrome" by a new treatment modality-application of the low level laser. Int. J. Clin. Pharmacol. Ther. 33, 208-211.

11. Basford, J. R. (1995). Low intensity laser therapy: still not an established clinical tool. Lasers Surg. Med. 16, 331-342.

12. Campana, V., Moya, M., Gavotto, A., et al. (1998). Effects of diclofenac sodium and He:Ne laser irradiation on plasmatic fibrinogen levels in inflammatory process. J. Clin. Laser Med. Surg. 16, 317-320.

13. Ternovoi, K.S. (1984). Analgesic laser therapy of patients with post-traumatic and involutional lesions of the musculoskeletal system. Ortop. Traumatol. Protez. 7, 1-7.

14. Clark I., and Umbreit W.W. (1954). Effect of cortisone and other steroide upon in vitro synthesis of condroitin sulfate. Soc. Exp. Biol. Med. 86, 558-561.

15. Castor, C.W., and Muirden K.D. (1964). Collagen formation in monolayer cultures of human fibroblast. The effects of hydrocortisone. Lab. Invest. 13, 560-574.

16. Smith, Q.T. (1962). Effects of cortisone administration on cutaneous collagen and hexosamine in rats of various ages. J. Invest. Derm. 39, 219-224.

17. Chvapil, M. (1957). Studies in fibroplasia. IX-Notes on the mechanism of he effect of cortisone on fibrogenisis. Phisiol. Bohemoslovenica. 7, 391-398.

18. Ruch, J.V. (1969). Action d'un glucocorticoide sur l'embryon et sur les tissus embryonnaires in vitro. [Doctoral dissertation]. Strasbourg, France.

19. Wali, M.A. (1983). Influence of corticosteroids on conective tissue. Indian. J. Dermatol. 28, 69-72.

20. Mester, E., Gynes, C., and Tota, J.G. (1969). Experimentelle unterschungen ober die wirkung von laser-straden auf die wundheilung. Z. Exp. Chir. 2, 94-101.

21. Mester, E., Spiry, T., Szende, B., et al. (1971). Effects of laser rays on wound healing. Am. J. Surg. 122, 532-535.
22. Mester, E., Korenyi-Both, A., Spiry, T., et al. (1973). Stimulation of wound healing by means of laser rays: clinical and electron microscopical study. Acta Chir. Acad. Sci. Hung. 14, 347-354.

23. Mester, E., Mester, A.F., and Mester, A. (1985). The biomedical effects of laser application. Lasers Surg. Med. 5, 31-39.

24. Saperia, D., Glassberg, E., Lyons, R.F., et al. (1986). Demonstration of elevated type I and type III pro-collagen mRNA levels in cutaneous wounds treated with helium-neon laser. Biochem. Biophys. Comum. 138, 1123-1128.

25. Kana, J.S., Hutschenreiter, G., Haina, D., et al. (1981). Effect of low power density laser radiation on healing of open skin wounds in rats. Arch. Surg. 116, 293-296.

26. Mester, E., Nagylucskay, S., Tisza, S., et al. (1978). Stimulation of wound healing by means of laser rays. III. Investigation of the effect on immune competent cells. Acta Chir. Acad. Sci. Hung. 19, 163-170.

27. Benedicenti, A., and Martino, A.R. (1983). La valutazione dell'incremento di ATP endocellulare in linfociti sottoposti a biostimulazione com luce laser $904 \mathrm{~nm}$ infrared (Protocollo sperimentale e proiezione clinico-aplicatine). Parodontol. Stomatol. 22, 9-36.

28. Boulton, M., and Marshall, J. (1986). He-Ne laser stimulation of human fibroblast proliferation and attachment in vitro. Lasers Life Sci. 1, 125-134.

29. Abergel, R.P., Lam, T.S., and Meeker, C.A. (1984). Biostimulation of procollagem production by low energy lasers in human skin fibroblasts cultive. Clin. Res. 31, 567-572.

30. Loevschall, H., and Arenholt-Bindslev, D. (1994). Effect of low level diode laser irradiation of human oral mucosa fibroblast in vitro. Lasers Surg. Med. 14, 347-354.

31. Karu, T.I. (1989). "Photobiology of low power laser Therapy". Chur:Harwood.

32. Friedmann, H., Lubart, R., Laulicht, I., et al. (1991). A possible explanation of laser induced stimulation and damage of cell cultures. J. Photochem. Photobiol. B. 11, 87-91.

33. Glassberg, E., Lask, G.P., Tan, E.M., et al. (1988). Cellular effects of the pulsed tunable dye laser at 577 namometers on human endothelial cells, fibroblast, and erytrocytes: an in vitro study. Lasers Surg. Med. 8, 567-572.

34. Lubart, R., Wollman, Y., Friedmann, H., et al. (1992). Effects of visible and near-infrared lasers on cell cultures. J. Photochem. Photobiol. B. 12, 305-310.

Address reprint requests to:

Valdir Gouveia Garcia, D.D.S., Ph.D.

Departamento de Cirurgia e Clinica Integrada

Disciplina de Periodontia

Faculdade de Odontologia de Araçatuba

UNESP

Rua José Bonifácio, 1193

16015-500 Araçatuba, SP, Brasil

E-mail: gouveia@folhanet.com.br 